\title{
CPV: Lessons from the First 100MW and the Explosion of Next Generation Technologies (Presentation Video)
}

\section{Adam Plesniak}

Adam P. Plesniak, "CPV: Lessons from the First 100MW and the Explosion of Next Generation Technologies (Presentation Video)," Proc. SPIE 9175, High and Low Concentrator Systems for Solar Energy Applications IX, 917502 (7 October 2014); doi: 10.1117/12.2067923

SPIE Event: SPIE Solar Energy + Technology, 2014, San Diego, California, United States 


\title{
CPV: Lessons from the First 100MW and the Explosion of Next Generation Technologies (Presentation Video)
}

\author{
Adam P. Plesniak, Arzon Solar, LLC (United States)
}

\begin{abstract}
The past decade has seen concentrator photovoltaics (CPV) technology transition from a few backyard experiments to an installed global capacity of well over $100 \mathrm{MW}$. With several utility scale power plants in commercial operation, the presentation will first focus on history and quality of performance since commissioning and overall customer satisfaction. Critical lessons learned from the process of designing, manufacturing and installing product for the utility scale renewable generation market are discussed. The presentation will reflect on how lessons thus far will guide CPV innovators through the flowering of Next Generation CPV technologies, from spectrum splitting optics to five junction solar cells, currently underway throughout the industry. Overall, CPV continues to serve as a robust platform for the new ideas and research needed to mature the higher performance and lower cost technologies critical for continued competitiveness of $\mathrm{CPV}$ in the renewable generation marketplace.
\end{abstract}

View presentation video on SPIE's Digital Library: http://dx.doi.org/10.1117/12.2067923 